Portland State University

PDXScholar

Dissertations and Theses

Dissertations and Theses

$11-17-1981$

\title{
The Effects of Correctional Education on Recidivism
}

William L. Hiser

Portland State University

Follow this and additional works at: https://pdxscholar.library.pdx.edu/open_access_etds

Part of the Criminology Commons, Education Commons, and the Psychology Commons Let us know how access to this document benefits you.

\section{Recommended Citation}

Hiser, William L., "The Effects of Correctional Education on Recidivism" (1981). Dissertations and Theses. Paper 3183.

https://doi.org/10.15760/etd.3172

This Thesis is brought to you for free and open access. It has been accepted for inclusion in Dissertations and Theses by an authorized administrator of PDXScholar. Please contact us if we can make this document more accessible: pdxscholar@pdx.edu. 
AN ABSTRACT OF THE THESIS OF William L. Hiser for the Master of Science in Psychology presented November 17, 1981.

Title: The Effects of Correctional Education on Recidivism APPROVED BY MEMBERS OF THE THESIS COMMITTEE:

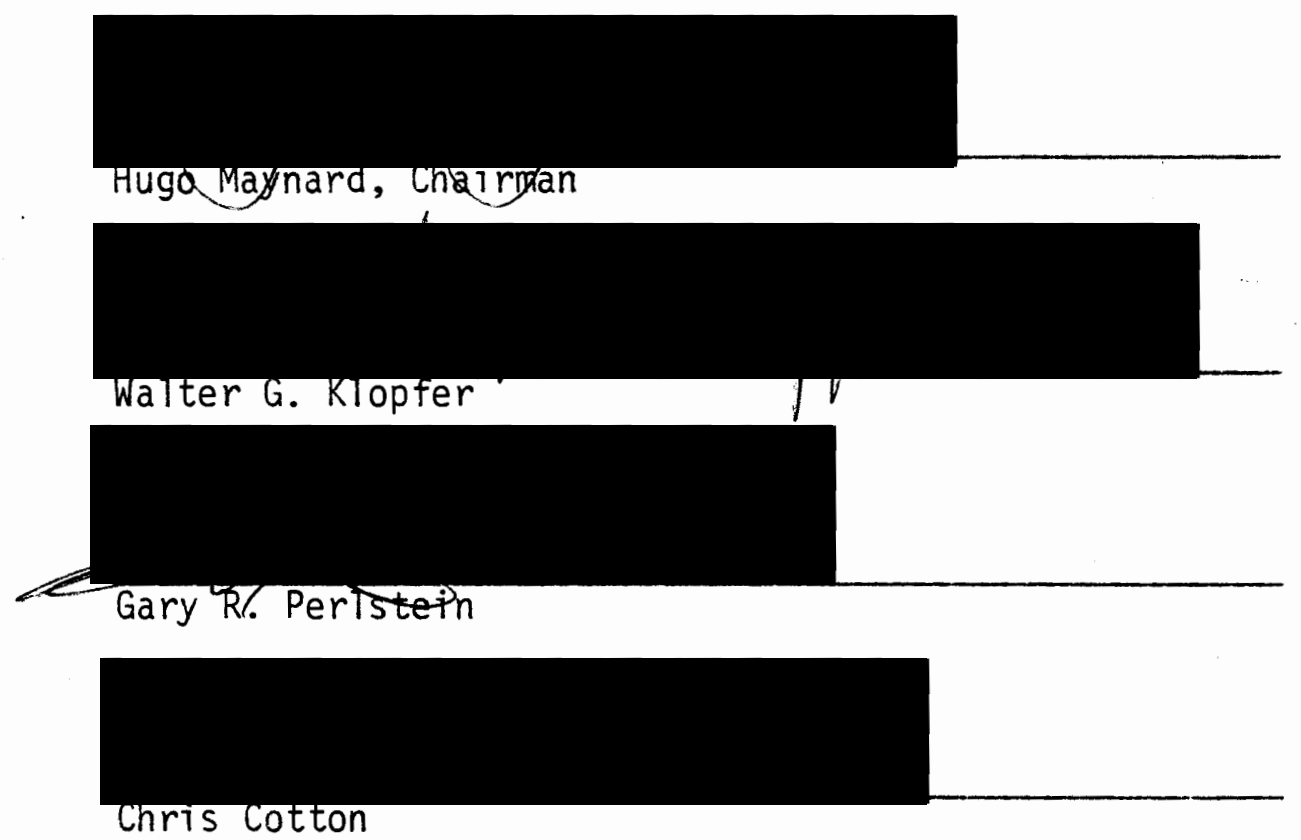

The effectiveness of programs intended to rehabilitate criminal offenders has been widely debated during the last decade. This thesis represents an attempt to evaluate the effects of education and training programs in particular, insofar as these effects have been measured in terms of recidivism.

One of the criticisms of rehabi?itation programs is that they have often been adopted and utilized in correctional institutions and even throughout state correctional systems without first being tested and 
proved as to whether or not they accomplish the purpose for which they are intended. The educational deficiency among prisoners as compared with the educational characteristics of society in general has often served as the rationale for providing educational opportunities for inmates of correctional institutions. While it is reasonable to assume that improving the level of education and vocational skills among criminal offenders will prove beneficial, there has been very limited information available as to the results of participation in such programs in terms of the effects on post-release behavior. Does the person who takes advantage of educational opportunities in prison have a better chance of succeeding as a citizen after he or she has been released from prison than the person who does not choose to be involved in these programs? This thesis attempts to evaluate the available evidence that is pertinent to that particular question.

An attempt has been made, in the study, to evaluate the evidence in three different areas of education: (1) basic and remedial education and G.E.D. training, (2) post-secondary education programs, including study release programs, and (3) vocational training programs. On the basis of the evidence, there is no clear effect on recidivism by programs in education. The thesis is concluded with an effort to evaluate the evidence that has been reviewed with conclusions and suggestions for further research offered that have seemed appropriate to this writer. 
THE EFFECTS OF CORRECTIONAL EDUCATION ON RECIDIVISM

by

WILLIAM L. HISER

A thesis submitted in partial fulfillment of the requirements for the degree of

MASTER OF SCIENCE

in

PSYCHOLOGY

Portland State University

1982 
TO THE OFFICE OF GRADUATE STUDIES AND RESEARCH:

The members of the Committee approve the thesis of William L. Hiser presented November $17,1981$.

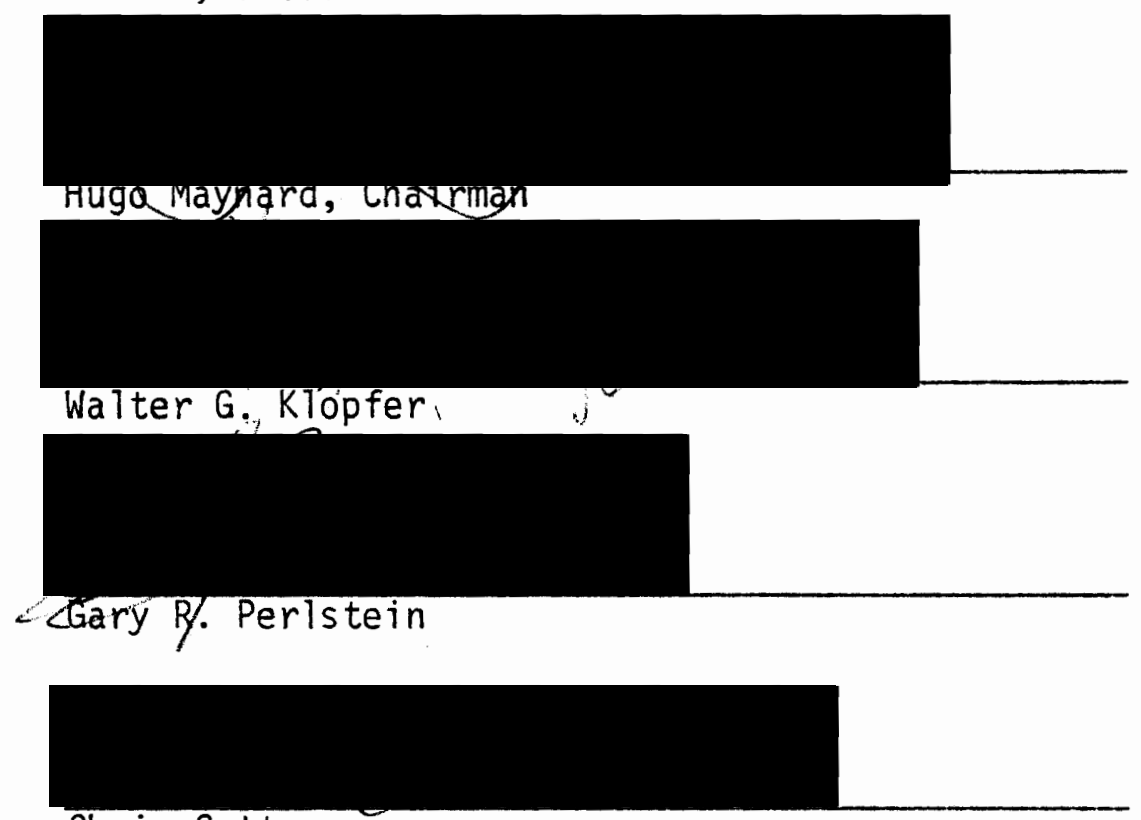

Chris Cotton

APPROVED:

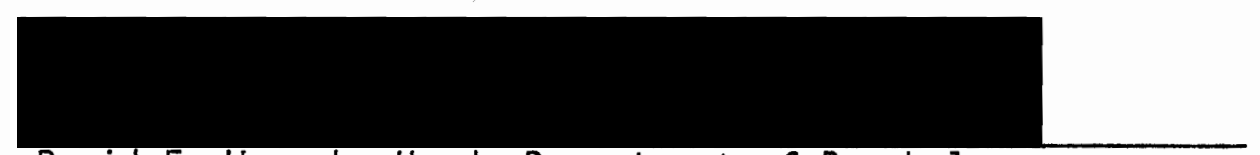

David F. Wrench, Head, Department of Psychology

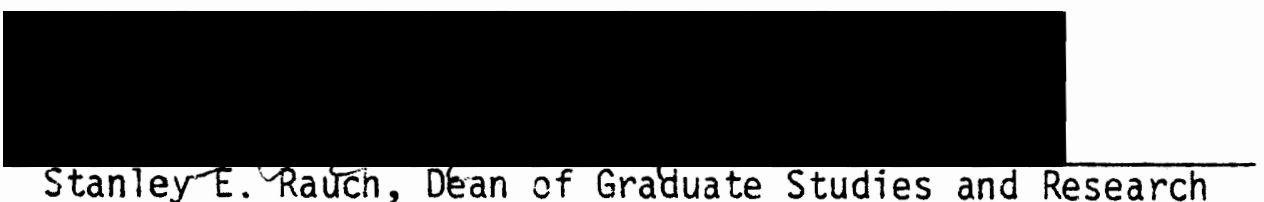

Stanley E. Rauch, Dean of Graduate Studies and Research 
TABLE OF CONTENTS

PAGE

ACKNOWLEDGEMENTS . . . . . . . . . . . . . . . .

CHAPTER

I INTRODUCTION TO THE PROBLEM ................ 1

Education and Rehabilitation ......... . 2

The Controversy over Education ........ . 4

A Brief Survey of the History of Prison

Education Programs........... 5

II METHOD ....................... 9

Introduction ............... 9

The Work of Robert Martinson ......... 10

Criteria for Choice of Studies for Review. . . . 11

Recidivism

Follow-up

III BASIC OR REMEDIAL EDUCATION AND G.E.D. TRAINING . . . 18

Educational Characteristics of Prisoners .... 19

Problems ................ 20

The Evidence . . . . . . . . . . . . 21

IV POST-SECONDARY EDUCATION PROGRAMS ......... 27

Study Release Programs .......... 30

$\checkmark$ VOCATIONAL EDUCATION AND TRAINING ........ 35

Vocational Training for Women Inmates...... 41 
CHAPTER

PAGE

VI CONCLUSIONS . . . . . . . . . . . . . . . . . . 43

Recommendations . . . . . . . . . . . 49

Basic and G.E.D. Education

Post-secondary Education

Vocational Training

A. SELECTED BIBLIOGRAPHY . . . . . . . . . . . . . . . . . 


\section{ACKNOWLEDGEMENTS}

I wish to express my appreciation to the members of the thesis committee for the time and effort they have given to this project; particularly: to Dr. Klopfer for help in the early planning and for editorial comment, to Dr. Perlstein for invaluable sources of information, to Dr. Cotton for friendly support throughout the project, to Dr. Grimes for editorial comments and corrections that have certainly improved the final draft, and especially to Dr. Maynard who patiently met with me on many occasions, providing constant encouragement to the effort of bringing the thesis to its final form. 


\section{CHAPTER I}

\section{INTRODUCTION TO THE PROBLEM}

My interest in the subject of this thesis goes back to my own experience as a correctional counselor at Idaho State Penitentiary from 1970 to 1972 . In that role, I was responsible for coordinating reports and making evaluation of performance for presentation to the parole board on behalf of those clients who were assigned to my caseload. Such evaluations were made on the basis of their involvement in programs. What were the effects of participation? Was there evidence of behavioral change, etc.?

I was also directly responsible for the supervision of both the work and study release programs. In time, I came to develop certain theories about the kinds of progiam involvement that I thought were most likely to bring about a change in thinking or attitude, and, hopefully, in behavior. I had a growing impression that those who were seriously involved in education programs were more apt to gain insights that could be helpful in understanding themselves or in developing a wider sense of their own social responsibility, than those who did not participate in such programs. While we had only limited evidence, at the time, to support that conclusion, there has been continuing research on prison programs that makes further evaluation possible today. 


\section{EDUCATION AND REHABILITATION}

Evident1y, a great many persons involved with corrections have assumed that education is a valuable, even critical component of the rehabilitation process. The State of New York, for example, after the Attica experience, has placed a great deal of emphasis on education as a tool of rehabilitation. Programs were designed by local colleges in the vicinity and arranged so that any student who began college-level work in prison would be eligible to continue at any of the participating colleges after his release. The director of the program described higher education as "humanizing and liberating" and felt it would open new pathways in the rehabilitation of prisoners. Prison Superintendent Harold Smith felt the costs of education programs could be justified by the savings realized as a result of rehabilitation: Since the annual cost of keeping someone in prison exceeds $\$ 15,000$ a year, he felt that taxpayers are well-served by "a college program that helps released prisoners stay out of prison" (Cuddey, 1977).

This belief in education as an effective tool of rehabilitation is widely shared. Some forty-six states were offering post-secondary education for inmates in 1976. A more recent survey, based on a sample of correctional institutions with populations over one hundred, indicated that al1 offered education programs, that about 40 percent of their clients participated, and that about 8 percent of the institutional budgets went to education programs (Bell et al., 1979, p. 3).

Literature on the subject reflects confidence in education which is regarded by some as "the primary strategy in the treatment process . . .," and as having the potential of breaking the cycle of 
circumstances that lead to crime--"poverty, sub-standard education and lack of job skills. . . If the inmate is prepared educationally for his return to society, we will be less likely to return to crime" (Galley \& Parsons, 1976). Others see great promise in post-secondary education programs in particular. "Undoubtedly, the greatest institutional resource available for the orderly future development of correctional education--both vocational and correctional--is higher education" (Marsh \& Adams, 1973, p. 138). Others believe that corrections education is finally coming into its own and gaining the recognition and respect in correctional circles it has not enjoyed in the past. At best, it has been tolerated, is often ignored, inadequately staffed and funded, but there is hope that correctional education "may, in the end, prove to be the most remarkable 'sleeper' in the history of corrections" (Reagan et al., 1973, p. 266).

Confidence in positive results through education has sometimes been carried to extremes. One writer seems to regard education as synonymous with rehabilitation. "The basic nature of education is change. Regardless of the purpose for a particular educational process, the end result is that somebody and/or something is changed" (Marsh, 1973, p. 20). A report to the Oregon Legislature in 1974 recommended extensive investment in correctional education and proposed that no new educational facilities be built within correctional institutions, and that education opportunities at local public institutions should be extended to all inmates in Oregon.

There exist excellent education facilities throughout the state. The goal of inside education activities should be placement of the individual in a community educational institution for 
continued education and training at the earliest possible time. (SaTmony, 1974, p. 59)

The legislature was not persuaded that such a policy was in the best interests of Oregon.

For quite different reasons, Dr. Leonard Zunin and Dr. Norman Barr (former chief psychiatrist with the Bureau of Prisons) offered a similar proposal.

The building of prisons on university campuses is the ... evolutionary direction for corrections to assume . . . We suggest that the next fifty prisons constructed in the U.S. be built on college campuses in each state. . . It would help educate the public to the fact that resolution of correctional problems is in its own best interests. (Marsh \& Adams, 1973, p. 139)

\section{THE CONTROVERSY OVER EDUCATION}

The discussion up to this point is not intended to suggest that confidence in rehabilitation programs is unanimous among professionals in corrections. Corrections personnel are generally aware of the debate that centers around the question of whether or not these programs are effective. A glance at some of the titles in recent literature on the subject reflects the controversy: "Faith in Rehabilitation Is Suffering a Collapse" (Holden, 1975), "Reform Is a Flop" (Malloy, 1975), "Nothing Works" (Martinson, 1974), "Rehabilitation Has Been a Failure" (Bailey, 1975), etc. To some extent, the disenchantment with prison programs might be explained in terms of the public mood related to the rebellion against necessary tax levels if these programs are to be continued. However, this should not obscure the fact that the public has become increasingly aware that several decades of emphas is on rehabilitation has not succeeded in reducing the crime rate or deterring 
criminal behavior. Since it is widely acknowledged that rising crime rates can be traced to repeat offenders, it is not surprising that "the country is in reaction against a humanitarian approach to criminals" (Serri11, 1975).

Furthermore, much of the controversy is generated from within the profession. In the light of research efforts by social scientists, many persons engaged in corrections have begun to question the validity of rehabilitation programs. Do they accomplish their intended purpose or succeed in reaching the goals for which they are designed?

A clear cut idea of what constitutes success obviously should be crucial, for offenders can only be discharged from hospitals, prison or probation order when they have successfully completed treatment. The aims and methods of rehabilitation are relatively clear but in a curious way there is hardly any discussion of a successful completion ... (Bean, 1976, p. 60)

To put it simply, there has been too little concern with accountability. Programs are introduced into the treatment process with little planning or effort to measure or evaluate what they accomplish.

In most cases, evaluation of educational programs, even when mandated, is less than adequate and, if present, consists of a gathering of opinions and fiscal accounting. There is no clear pattern in program evaluation of what exists, what has been successful, or what has failed. (Bell et al., 1979, p. 5)

\section{A BRIEF SURVEY OF THE HISTORY OF PRISON EDUCATION PROGRAMS}

A brief review of the history of prison education seems appropriate at this point as background for the subject we are considering. The following summary depends mainly on the work of Kenneth Martin (1973). Readers interested in more detail on the subject will find Martin an excellent resource. 
Some scholars regard correctional education in America as being only forty to fifty years old. That may be true of formal, certified programs. However, if the wider definition of education is accepted, so that attempts to change attitudes, behavior, and skills are included, the history of prison education is as old as prisons themselves. Teaching basic reading and writing skills for religious purposes can be traced back at least to the beginning of the nineteenth century. These early efforts led to the first established prison school in Maryland early in the century and to the hiring of a teacher and the founding of a library in a Pennsylvania prison in 1844. Shortly after that time, New York passed a law providing for teachers to be hired for all state prisons.

These early efforts were based on the recognition that ignorance and lack of education were contributing factors in crime. The prevalent philosophy, however, was that "hard work and penitence" would lead to reform, and the idea soon developed that has continued to modern times, that prison expenses can and should be offset by prison labor.

Not until the last of the nineteenth century was an organized system of formal education developed. (As late as 1870, only about eight thousand out of an estimated twenty thousand prisoners in America were receiving any form of instruction.) In 1870, The American Prison Association was formed--later to be known as the American Correctional Association--and an organized attempt was begun to establish professional standards in prisons and introduce humanitarian and rehabilitative principles of treatment. 
Reform and not punishment was the aim of the new movement. To begin with, the programs were highly structured and committed to the notion that discipline and regimentation were necessary to reform an inmate. Later, these programs were modified and ideas such as the indeterminate sentence, coupled with education and employment, were introduced. Also, a system of rewards for good work and behavior (good time) which could lead to parole or release consideration was added. By the end of the century, the hope was well-established that clients might be expected to be better men and women when they were released than when their confinement began.

The development of prison industries and manufactured goods soon led to conflict in the free market. As a result, it became standard practice to manufacture goods and equipment on 1y for state agencies. This problem, along with the arrival of the great depression, slowed prison programs considerabiy. Where three-fourths of the prison population in America was employed in 1885, less than half were employed in prison workshops in 1940.

Idle time, therefore, became a matter of increasing concern. This led to a renewed emphasis on rehabilitation and in 1930, the federal prison system appointed teachers at all federal prisons and allocated funds for education purposes. By 1933, some 60 percent of all federal prisoners were enrolled in classes. Later, the federal system and some states began to make education compulsory for illiterate inmates.

About this time, formal relationships were established between prison programs and education departments in many states. Now, in New York, for example, prison teachers are licensed and vocational and 
academic diplomas and certificates are awarded.

At present, education programs have obtained a limited degree of sophistication through imaginative innovations such as programmed and unit instruction, self instruction methods, operant enforcement techniques, audio visual aids and computer programing. (Martin, 1973, p. 61)

The concept that education has a socializing effect also developed during this later period, along with the development of the behavioral sciences with emphasis on self-realization and self-direction as the means to social adjustment. In 1968, thirty-six states offered college-level work with about 1 percent of the prison population enrolled. A recent survey indicates that 80 percent of the states now offer education through the college level and that inmate involvement ranges from 20 to 50 percent.

The history of prison education helps place the rehabilitation ideal in perspective. Given the close relationship between education and rehabilitation over many years, it is unlikely that prison administrators are going to dissociate themselves from rehabilitation efforts without overwhelming evidence that such programs are failures. Our intention in this study is to review the evidence of research concerned with evaluating the effects of prison education programs, recognizing that in doing. so it will be necessary to make some sort of judgment as to whether or not the research is adequate. Secondiy, I will address the question of whether or not we can conclude, on the basis of available evidence, that prison education and training programs are beneficial in reducing recidivism rates. 


\section{CHAPTER II}

METHOD

\section{INTRODUCTION}

There were scattered research efforts to measure the effectiveness of education and other rehabilitation programs beginning in the early 1940 s and continuing into the 1960s. However, either the results or the methods were often inconclusive and the work was often too isolated to be taken seriously. Not until Robert Martinson and his associates reported on the research results available at the time was there any systematic evaluation of the evidence. (Their work was begun in 1966 but the results were not published until 1975.) Our study will be concerned with research information that has been published since 1970 but not with the studies reviewed in their work, except for occasional references to work that is still frequently cited in more recent literature. We will be concerned, however, with the results and conclusions of their work and its continuing impact on education programs.

The criteria for choosing what material to include in our review of literature on the subject relates to the competence of the studies themselves and whether or not they address the concerns of this thesis. For the most part, we have not included: (1) studies which made no use of a control group as a basis for comparison, (2) research that was not concerned with recidivism as a measure of success, and (3) research results with inadequate post-release follow-up. 


\section{THE WORK OF ROBERT MARTINSON}

One could hardly discuss the effects of rehabilitation programs without reference to the work of Martinson and his associates. In 1966, they were appointed by the New York State Governor's Special Committee on Criminal Offenders to do a comprehensive study of the effects of rehabilitation programs. The State of New York was planning a major shift in emphasis from custody to rehabilitation and evidently hoped to gain statistical support for the new approach from the results of the study.

However, by the time the information was completed and the results were available for publication, Martinson found that the committee that had commissioned the work was no longer interested. Not only did they decline to publish the report, but, according to Martinson, they also refused to allow him to make the information public. Only after some of the information in the report was subpoenaed as evidence in a trial and had become part of the public record did Martinson and associates succeed in having their work published.

The work of the Martinson group addressed the following question: does a correctional facility that is committed to offering rehabilitation programs such as education and vocational training, turn out more successful individuals than a prison which is committed to a custodial philosophy? Their answer, from the evidence they collected: "If this is true, the fact remains that there is very little empirical evidence to support it." The research evidence available at that time seemed to "provide us with no clear evidence that education and skill development programs have been successful" (Martinson, 1974). Acknowledging that there were problems in the study such as disparity in both programs and 
populations, as well as the question of consistency in treatment method, the group nevertheless felt that:

- . we can be reasonably sure that, so far, educational and vocational programs have not worked. We don't know why they have failed. We don't know whether the programs themselves are flawed or whether they are incapable of overcoming the effects of prison life in general. . . or whether they lack applicability to the world the inmate will face outside the prison... What we do know is that to date, education and skill development have not reduced recidivism by rehabilitating criminals. (Martinson, 1974)

As might be expected, the results of Martinson's work have been controversial. My own view is that his conclusions may be colored by reaction to the opposition he encountered from established correctional authority. In his defense, it does not seem that he is saying that the evidence against rehabilitation programs is overwhelming but that evidence in support of such programs is uncertain or inconclusive at best. Nor does he suggest that such programs have failed to meet other goals. Looking at effects on variables other than recidivism, he found that:

A1l kinds of things are happening . . . There is clear and unmistakable evidence that we can teach an illiterate to read in prison, that you can impart vocational skills in institutional training programs ... (Martinson, 1975)

However, very little evidence exists that education and training programs have statistically significant effects in reducing recidivism.

\section{CRITERIA FOR CHOICE OF STUDIES FOR REVIEW}

I submit that if the work of Martinson and his colleagues leads to further evaluation and research, they will have served their profession well. Nevertheless, since their work concerns research that was reported in the 1960s, there is clearly a need for review of the evidence that has been collected since that time, a concern noted by 
others also.

The study [Martinson's] examines research on programs conducted before 1967. It was only after 1967 that the prison reform movement got into full swing. Until that time, programs .. . were disorganized and understaffed . . . Community programs . . Were almost non-existent in most states. . . Furthermore, one of the areas in which corrections was most deficient prior to 1967 was research. (Serri11, 1975)

This is not intended to suggest that there were no competent education programs before 1967. Examples of excellent education and training programs in existence as much as twenty years earlier could be cited. Speaking in general terms, however, the surveys to which reference was made earlier indicate that both the number of states offering education programs and the percentage of inmates involved in such programs have increased dramatically since 1968. Federal funding for such programs, which became available about this time, may account for the momentum in the development of prison education which has continued until the present time. This thesis will be concerned, primarily, with research that has been published or reported since 1970 .

The criteria used by Martinson's group in selecting studies for review included the following. A study had to include an evaluation of the treatment program that employed some independent measure of improvement (such as recidivism), and which made use of a control group as well as an experimental group for purposes of comparison. Studies were excluded for reasons such as: insufficient data, statistical tests which were not appropriate, data not available for review, samples that were too small or which seemed incompatible with the study populations, etc. (Martinson, 1974). 
While the criteria to be used in this thesis are similar to those used by Martinson's group, they were not derived from his work but were established independently before the writer became familiar with Martinson's work. Also, there are some differences in the standards to be applied in this study. We will be concerned with whether or not the study made use of a matched control group since this assures us that the experimental group is representative of the population with which the study is concerned. However, our review of the evidence will not attempt to evaluate the tests by which the results are measured or to present data for reader review. It will be assumed that interested persons can refer to the original resources for this kind of information.

Recidivism

Since some determination is necessary by which to judge the effectiveness of programs, we will also be concerned with recidivism as the measure of program success. (The Martinson study made use of other measures of improvement as we11.) Obviously, recidivism is not the only measure of the effectiveness of programs. Other things such as (1) the length of time an inmate remains free after his release, (2) his employment success, (3) such things as adjustment to prison life as measured by work reports, disciplinary reports, and good time,

(4) changes in attitude as measured by personality inventories, and (5) educational achievement measured by tests and grade progress, are all indices of the effects of programs. Then why emphasize recidivism as a measure of change or improvement? 
Professionals are apparently divided on the question, perhaps because so many related questions are involved with recidivism. If someone is not returned to custody during the follow-up period, are we assured that he has adjusted to society, and therefore benefited from participation in programs; or does it mean that he has become more clever and careful in the art of crime and simply has not been caught? And what about differences in parole policy? Obviously, a tough parole policy may lead to more violations than a lenient policy in which supervision is minimal. (The effect of supervision may account for the lower recidivism rates among those who receive final release from prison as against those who are paroled.) While appropriate controls can eliminate some uncertainties--for example, including an equal percentage of parolees in both the experimental and control groups--it is clear that some questions will remain. However, I think that we must assume that in the long run, these things average out and that successful citizenship for a given period of time can be used as a valid measure of program success.

To this must be added the assumption that recidivism is the bottom 1 ine when it comes to measuring the effect of programs. For one thing, the cost of rehabilitation programs is in addition to the cost of confinement. Surely legislative groups and the public have a right to know whether or not programs are viable in terms of their objectives. Do treatment programs have an effect that is different from the effect of imprisonment itself (Kassenbaum, Ward \& Wilner, 1971, p. 207)? I submit that even the clients who are served by such programs will benefit from answers to these questions. If 
treatment programs do not rehabilitate, then officials in corrections must be prepared to justify programs on other grounds.

A review of expert opinion on the subject suggested that:

Recidivism is far and away the prime criteria for judging the success or failure of a rehabilitation program. So far, it appears that there is little correlation between a person's apparent success in performance in his program and the likelihood of his abandoning his anti-social ways. (Holden, 1975) Also:

It is recommended that the design of program evaluations include procedures for measuring the impact of education programs on inmates after program completion and after release. In this context, criteria such as inmate needs assessment, inmate response to the program, post program followup, and recidivism should be given priority in evaluation. (Bell et al., 1979, p. 94)

While this study will be mainly concerned with research that uses statistics on recidivism, we will also take note of some studies which offer other kinds of evidence if it can be concluded that the results are likely to be related to the recidivism question.

\section{Follow-up}

The other question to be addressed has to do with the length of follow-up. The national report cited earlier states that:

Little if any attention has been given to the measurement and/or assessment of post program followup, post release followup or recidivism rates in the evaluation of correctional education programs over the last five years. (Bell et al., 1979, p. 94)

The work of Daniel Glaser and others provides a fairly clear indication of the follow-up necessary to determine recidivism rates. His original study of this question was based on a 10 percent sample of ten thousand male prisoners released from federal institutions in 1956 who were tracked for four years. Failure was defined as returning to 
prison for parole violation or receiving a new sentence for a felony offense. In this early study, Glaser found a recidivism rate of 35 percent during the first four-year period after release. Beyond this initial period, the failure rate seemed to level off, and while some additional failures did occur later, they were so widely dispersed that Glaser reached the conclusion that four years of follow-up provided . conclusive evidence on recidivism. On the basis of his work, a twoyear follow-up period became widely accepted as the minimum standard in determining recidivism. However, his later study alters that conclusion (Kitchener, Schmidt, \& Glaser, 1977). This report extended the follow-up study of the original group to eighteen years and included 93.2 percent of the original sample. The research indicated that 37 percent of the clients had no known violations after eighteen years. The later study also included a sample of federal prisoners released in 1970 which shows some acceleration in recidivism after the first year, rising to 34 percent after two years and 51 percent after five years. Again, he found a kind of leveling off after four years with 75 percent of the failures occurring within four years and 80 percent within five years. On the basis of the later information, he recommends that the follow-up period should be extended beyond the earlier standard.

Reference should also be made to the careful work of Kassenbaum, Ward, and Wilner on this subject (1971, pp. 211-12). Generally, they found that getting back information on parole violations took more than a year and they determined at least thirty-six months of follow-up was necessary to arrive at any valid measure of recidivism. Their work, 
along with Glaser's studies, indicate that a three-year follow-up period is necessary in determining recidivism.

In the chapters that follow, we will be concerned with available evidence of the effect of education on recidivism at three levels. Chapter III will be concerned with post-release outcomes for those who participated in basic education and G.E.D. preparation while they were in prison. Chapter IV will be concerned with the post-release effects of college-level education programs. Chapter $V$ will be concerned with measurement of the effect of vocational training programs. In all of these chapters, we will attempt to review the effects of these kinds of training vis-à-vis the question of recidivism. Finally, we will try to evaluate the evidence and offer recommendations that seem appropriate as a result of the study. 


\section{CHAPTER III}

BASIC OR REMEDIAL EDUCATION AND G.E.D. TRAINING

The case for providing basic education and G.E.D. training for prisoners has been well-documented in the literature on prison education programs. The fact that prisoners tend to be socially disadvantaged due to their educational deficiency is reason enough for providing programs designed to correct the problem. Therefore, the question might be raised: why be concerned at all with the long-range effects of prison education at this leve1?

It is not the purpose of this study to cite research evidence in order to justify providing educational opportunities to prisoners. This writer agrees that such programs are necessary whatever their effects on recidivism may be. Nevertheless, any evidence of these effects remains important to the subject of this thesis. In addressing the question of the effect of education on recidivism, it would surely be a mistake to ignore as large a part of the corrections education effort as that which is represented by these particular programs. For that reason, even though the evidence we have to offer is limited, this section on basic and G.E.D. education programs in prisons has been included in our study. 


\section{EDUCATIONAL CHARACTERISTICS OF PRISONERS}

One of the most widely used references on this subject are the statistics and conclusions of Daniel Glaser. His work, cited by Salmony (1973, pp. 15-17), indicates that in the late 1960s, the federal prison population had an eighth-grade median education compared to a tenthgrade median for the general population of the U.S., 80 percent of the prisoners were not high school graduates, and less than 3 percent had taken any college work. Even more important was the fact tests and records indicated that 30 percent of the prisoners were functionally illiterate.

Later surveys showed little change. Unofficial estimates were cited in 1973 (Reagan et al., 1973, p. v) suggesting that from 20 to 50 percent of the prisoners in America could not read nor write, at least 50 percent had not completed the eighth grade, and as many as 80 percent among youthful offenders were 111 iterate. Some variation was probably to be expected in different parts of the country and the statistics may not have seemed appropriate to some prison situations.

Some analysts have reached somewhat different conclusions. In a keynote address to the International Conference of the Correctional Education Association in 1976, it was noted that age and education characteristics among federal prisoners were changing. Prisoners are older (about thirty), better educated (ninth grade + ), and more intelligent than they were a decade earlier (University of South Florida, 1976). Statistics from the latest national survey (Bell et al., 1979, pp. 1-2) lend some support to this trend, indicating about one-third of the prison population of the U.S. has less than an eighth-grade education, 
another one-third have not completed high school, about 4 percent have taken some college work, and most inmates function at a level two or three grades below their school completion level. In spite of the fact some change was indicated over the last decade, there can be little doubt that most prison inmates are still deficient in education cf. to the general population. These facts had been recognized for as long as professionals in corrections have been evaluating programs, and it should be clear that education at this level will continue to receive priority and support.

However, even though studies of treatment effects are not necessary to justify basic education programs, they are useful for other reasons. For example, we need to know if some individuals or groups benefit more than others. Are some minority group members, or certain age groups more likely to gain from the experience than the general prison population? Are some approaches more effective than others? Reagan et al. (1973, p. 250) emphasized that most clients have failed in the traditional system and if traditional methods are employed in prison education programs, they will probably fail again. On the other hand, research which evaluates different methods may lead to more effective educational systems in prison.

\section{PROBLEMS}

There are certain problems to be noted with reviewing evidence in this section. Some studies do not define any time frame for participation in prison school programs. No clear indication is given of how long the subjects were enrolled in the prison school, whether or not 
they completed an academic term, or what academic achievement or educational gains were made. However, some studies have been included which offer other important evidence in spite of the fact that the extent of involvement in education programs is not clearly defined, or if the weakness was recognized and accounted for in the study.

\section{THE EVIDENCE}

In his early work, Glaser (1964, pp. 275-80) found education had a significant effect only for those persons who were extensively enrolled during prolonged confinement. Those who participated for at least three years had a 30 percent recidivism rate compared to a 48 percent rate for those who did not participate. On the other hand, those with short-term involvement had higher than average recidivism rates.

Martinson and associates (1975) reviewed eight studies that were concerned with the effects of institutional education. They found those who participated in education and skill development programs had lower rates of recidivism than nonparticipants, but the differences were not statistically significant. They also found a more positive effect for certain combinations of treatments. A program which combined tutoring and group therapy had a more positive effect as measured by personality tests than did either group therapy or remedial reading when those program effects were measured separately. It was not known why the combined program was more effective or how long the attitude change would last (Lipton, Martinson, \& Wilks, 1975, pp. 575-80).

Taking the effect of educational programs as a whole, Mace (1978, pp. 133-39) found "that the education program did have a positive, 
sustaining influence in improving post release conduct." His study includes graphs of the recidivism rates for both the experimental and control groups after four years of follow-up. At the end of the last year, the difference in recidivism was significant to the .003 level of confidence. He also found those enrolled in education programs had a better record in terms of escape attempts and disciplinary infractions than members of the control group. Parole reports indicated the experimental subjects had a better attitude than the control subjects, although this was recognized as a matter of subjective judgment. Another difference found was the experimental group members had higher monthly incomes during the follow-up period than the control group of nonparticipants. It is well-established in this study that employment and income are related to parole success.

Examining the effects of different levels of education, Mace (1978) found that the effect of G.E.D. training was not statistically significant, al though their success rate was four times their failure rate, among those who participated. He also found that success on parole was higher for those who completed the G.E.D. than for those who participated but did not receive the diploma.

Definitive conclusions based on these findings should be cautiously drawn, but evidence presented regarding the total education program would tend to favor the education group as a whole, and statistically, for those completing the G.E.D. and suggest that education had a positive influence on successful post release conduct. (Mace, 1978, p. 134)

The results of a study published by The Survey Research Center at Oregon State University are similar (Mason et al., 1978). Based on a random sample of two hundred male clients released from Oregon correctional facilities in 1974, the authors found that completion of work 
for the G.E.D. had a positive effect in combination with certain other factors. Those who completed the G.E.D. and had two or more dependents after their release had the most stable work history of any of the treatment groups, during the follow-up period. On the other hand, G.E.D. graduates with a history of several adult convictions had very poor work success after their release. A positive correlation was found for the effects of education in conjunction with the number of dependents and a negative correlation was found for the effects of education in conjunction with a significant criminal history, such as prior record, property offenses, and trust violations. The authors noted, however, that 80 percent of those who participate in education programs do not have this kind of background and that prison education is associated with post-release success for most men who participate. They also felt that the attributes of some young offenders with minimal offense records, might account for their success on parole rather than their participation in education programs.

- . we suspect that people with certain attributes volunteer to participate and the attributes which are associated with participation may be the same as those associated strongly with post-release success. (Mason et al., 1978, p. 9)

Those with extensive records or an above average number of trust violations, who also had completed the G.E.D. or had earned college credits, had the poorest post-release records. They were employed less, earned less money, and remained free for a shorter time than any other group in the sample. This not only suggests criminal history has a stronger effect than treatment programs, but may also suggest education has a negative effect for certain people such as the manipulators, those who enroll to impress the parole board, and the 1ike (pp. 34-36). 
Another study reports the effect of study and work release programs at the Middlesex County Corrections Facility in Ballerica, Massachusetts (Beha, 1977). The recidivism rate of comparable groups for the three years prior to the introduction of these programs was used as a baseline in the study. The results of the study seem positive. Those who participated in work or study release programs and were then released in 1972 had lower recidivism rates than the baseline rate. The author felt the programs in combination, and education release in particular, significantly reduced recidivism. However, statistical measures are not included in the report and there is not adequate information on the length of time subjects were involved. In addition, the length of the follow-up period was only twelve months.

Al though their report was concerned primarily with the effects of group counseling programs, which were widely used in the California system, the work of Kassenbaum, Ward, and Wilner (1971) deserves attention, since they also measured the effects of education programs. The effect of education in combination with group counseling was not found to be significant. However, the level of education completed did seem significant. Those who had completed high school and less than a year of college work had lower recidivism rates than the control groups or other participants in education programs, lower rates even than those who had completed more than a year of college work (pp. 224-25).

For the most part, this survey of research effects is concerned with education programs for aduits. However, there are some studies on juveniles which may be appropriately included in the review of education effects at this level. A Georgia study cited by Stoughton and Reagan 
(1973, p. 75) concerns the effect of institutional treatment and education programs as measured by the wechsler I.Q. Test and the California Test of Personality, both of which were given at admission and again just prior to release. The sample consisted of 117 inmates, predominately black males, whose average age at admission was thirteen years, nine months, and at release, fourteen years, two months. The average stay at the institution was about six months. "Those in the sample showed significant improvement in both the I.Q. and personality tests and it was concluded that the inmates do profit from their stay at the center."

An interesting study of juvenile education efforts was reported in a Canadian journal (Csapo et al., 1976). Ten hard-core juvenile probationers, who were high school dropouts, were compared with another group of ten dropouts having no juvenile records, and with a third group of probationers who were still in school. In the study, cash rewards were offered for school achievement. Surprisingly, the hard-core dropouts made the most progress, surpassing the other group of dropouts in their achievement. Follow-up of the groups after their release found no difference in the rate of continuing offenses among the three groups.

One important study, in which education as a treatment effect is mixed with other factors, is Taintor's (1977) lengthy and detailed analys is of D.V.R. services among youthful offenders in Florida. These extensive services included a full evaluation; counseling and guidance; medical, surgical and psychiatric therapy; vocational training; remedial education; comrephensive rehabilitation services; maintenance; 
transportation; and job placement. The author reports that:

. . the focus of this study is actions taken to rehabilitate the youthful offender which are intended to end his criminal career before it starts and return him to society as a youthful and productive member. (Taintor, 1977, p. 3)

The study compares the records of 2,542 youthful offenders under the supervision of The Florida Division of Youth Services (DYS) who were referred to the Department of Vocational Rehabilitation (DVR) for services, along with another 429 cases who were not under DYS supervision but were referred to DVR from probation status. This experimental group of 2,971 children was compared with a control group of 1,313 chi1dren who were supervised by DYS but not referred to DVR. Taintor found a "strong positive relationship. . . between receipt of DVR services and recidivism as measured by recommitment subsequent to furlough" ( $p$. v). He found the probability of recommitment was almost 10 percent for the control group compared to 4.4 percent for those referred to DVR. For children receiving significant DVR services, the probability of recommitment dropped to 2.8 percent and for those classified "rehabilitated/closed," it was slightly less than 1 percent. "These data indicate that DVR does have a significant effect upon rehabilitation of youthful offenders. These services do seem to reduce the amount of recidivism" (p. 305). While the study offers no evidence for the separate effect of education, it provides conclusive evidence of the fact that rehabilitation services can be effective among youthful offenders. 
CHAPTER IV

\section{POST-SECONDARY EDUCATION PROGRAMS}

Reference was made in the introduction to this writer's experience as a correctional counselor. I came to the personal conviction that substantial participation in college-level work, in particular, would be reflected in recidivism rates. Numerous references could be cited from the literature in support of that conviction. For example, Galley and Parsons (1976) suggested that: "Given the highly technical nature of contemporary society, a high school completion or basic trade and technical education are not usually comprehensive enough to overcome recidivism." These authors indicated, however, that post-secondary education programs do have the potential to reduce recidivism and noted the widespread belief in college-level work was shared by others, since education was available to inmates in forty-six states in 1976 . These programs included campus release study for some inmates, estimated to be between 5 and 10 percent of the total number of inmates enrolled in college study programs.

Is college-level study more effective in reducing recidivism than other types of education and training? One study addresses this question directly (Lewis, 1973). Reference is made to an experimental education program at Camp Hill, Pennsylvania, which the author describes as follows:

The program was designed to expose its students to materials and issues of inherent interest that would help them to define 
a sense of personal identity and to develop a sense of values consistent with those prevalent in society. (Lewis, 1973)

The program was reported to be well-received by inmates and there was evidence of positive short-term effects, but not of effects that continued after release. The follow-up was extended over a period of thirty-three months, after which about one-third were recidivists and another one-third were chronically unemployed. Psychological tests were used to measure values and attitudes. No significant differences were found between the former humanities students and other comparison groups. The author concluded these data did not indicate "any effects that could be attributed to the humanities program."

We noted earlier that Mace (1978) found short-term, positive effects among all participants in prison education programs. Unfortunate$1 y$, there were no significant effects on recidivism for those who took college-level work and he indicated he was puzzled by these results. While their success rate was notable ( 83 percent), the differences in recidivism for this group compared to the control group was not statistically significant. Mace thought this might be due "to the limited number of participants and the scant offerings of college courses" ( $p$. 133). He concluded that as college-level education efforts are expanded, further studies may produce different results.

Positive results are indicated in a study of the effects of vocational and post-secondary education programs supervised by the Windham School District in Texas (Monroe et al., 1975). The study population consisted of 6,693 inmates who were released from custody in 1973. About half were paroled and the other half were discharged. The sample consisted of Group I, 411 clients who were graduates of vocational 
training; Group II, 180 clients who graduated from post-secondary education courses; and a control group of 175 clients, matched on the basis of age, race, sex, I.Q., and release method. In order to match the three groups, they were reduced to seventy-five members for each group. Further attrition, due to moving and early recidivism, left Group I with sixty clients; Group II, sixty-one; and Group III (the control group), fifty-seven members. The groups were well-matched on demographic characteristics except that Group II had a higher percentage of parolees than the other groups.

Determining the rate of recidivism among the sample groups was a major concern of this study. When the data were collected and organized, both treatment groups had a recidivism rate of 12-13 percent compared with a 24 percent rate for the control group. The control group also took three times as long to find work as members of the treatment groups. Therefore, a positive effect from participation in education programs was clearly indicated.

An evaluation of the higher education program at Huntington, Pennsylvania used different factors to measure effect (Stroman, 1973). A total of 174 inmates were enrolled for a minimum of 3.5 credit hours. Courses in psychology, economics, sociology, and English were offered. It was assumed those with shorter sentences would be enrolled for only a few courses while those with longer sentences would have the opportunity to earn more credits. Also, a few with demonstrated ability to do college work, and who could get the proper security clearance, would be eligible for study on campus at Juniata College in Huntington. 
Short-term measures of success after one year were as follows: 113 students (67 percent) had completed courses and earned credits. Eighty students (73 percent) had completed more than one course, and three persons had completed four courses. A questionnaire was used to evaluate inmate response to the program: 73 percent reported the program helped them understand themselves better; 63 percent said it helped clarify their post-release goals; 73 percent thought it would help their post-release adjustment; 64 percent said it improved communication ski11s; 58 percent said it increased their desire for education. Effects on prison conduct were also measured and significant improvement was noted. Misconduct reports for the participating group dropped from 42 percent before entering the program to 21 percent after enroliment. The author reports the use of the Chi Square Test indicated a significant difference.

By a number of indices, improved inmate adjustment within S.C.I.H. (State Correctional Institute at Huntington) occurred as a result of the programs. Most inmates reported gains in self-insight, communication skills, preparation for the future, desire for more education and better adjustment as a result of involvement in the program. Furthermore, a statistically significant reduction of misconducts occurred after entrance into the program. The above evidence is also used to indicate the inmates are better prepared for release from S.C.I.H. (Stroman, 1973)

This last conclusion, of course, can only be accepted as inference. Unfortunately, the study offers no evidence on recidivism.

\section{STUDY RELEASE PROGRAMS}

Reference has already been made to campus release study for some inmates. Many of these programs are evaluated as separate programs, and are distinguished from on-site college study programs for prisoners. 
They were very popular about a decade ago and are still continuing in some states. Oregon was one of the states making wide use of this type of program with eight study release centers in operation in various cities around the state in 1974 .

By means of a grant from The Office of Economic Opportunity, a San Francisco firm attempted to evaluate the effectiveness of Newgatetype programs. According to Salmony (1974, pp. 164-72), a sample of 995 participants was selected from various program locations and both a control group and a comparison group were identified. However, Salmony's report makes reference only to the comparison group. He indicates that members of the experimental group and the comparison group were both released to parole status. After a two-year follow-up, the results showed 78 percent of the experimental group were still employed or in school, compared to 60 percent for the comparison group. There were fewer drug or drinking problems among the Newgate members ( 81 percent of the students were not involved vs. 58 percent of the comparison group members), and less illegal activity and more interest in continuing education were reported by the students than by members of the comparison group. On the basis of Salmony's report, some weaknesses in the study must be inferred. Apparently some of the Newgate students on study release status were not distinguished from others on parole, so that follow-up data are questionable. Also, recidivism was defined as being returned to prison in this study, whereas in other studies it is defined as a new felony conviction and/or being returned to prison. Nevertheless, an overall positive effect is indicated for education programs in spite of the apparent weaknesses in the study. 
Ohio's experience with study release parallels that of Oregon. The program in that state began with large enrollments (two hundred study release students the first year and three hundred the second year). The attrition rate was high with a 50 percent dropout rate the first year and a 40 percent rate the second year. Students were required to carry a full load (twelve credits) but were given a full year to complete one quarter's work. Evaluation of the program noted the selection criteria were probably not adequate. Prisoners enrolled in classes for a variety of reasons. "Most begin because they hope it will impress the parole board, but this does not seem to provide adequate motivation for continuing"; which leads the author to conclude that "In spite of Newgate's publicity... it has not been an unqualified success and is being phased out in Ohio" (Wooldridge, 1976).

Minnesota took a more cautious approach to study release (Cleneden et al., 1979). Participants enroll as full-time students for college work within the institution. Group counseling is an integral part of the prison education program and is intended to provide guidance and support. Those who are successful in completing work in prison may become eligible for campus release study. Either at the time of their release on parole or shortly before their parole dates, they are moved to a hal fway house on the University of Minnesota campus, where they are expected to reside until they have completed two quarters of work.

The Minnesota Newgate Program also attempted to learn if study release programs tend to select winners who would succeed on parole whether or not they participated in campus release study. In response to this concern, no reference is made to criminal records in the 
selection process except for reference to heavy drug use. Enroliment in the program is voluntary and candidates for campus release study must be parole-eligible in from six to eighteen months after admission and must have demonstrated ability to do college work. Compared to the general prison population, Newgate students were slightly older, had a smaller percentage of minorities, a higher number of prior convictions, a better education background, and longer sentences.

After the program had been in operation for five years, a followup study was undertaken to determine the effect of the program on recidivism rates. The study showed a success rate of 73 percent. However, the author cautions against misinterpreting the results, since the follow-up was not adequate in all cases. "Success as defined here means that an offender has been out of prison for a period ranging from 6 months to 5 years without committing a serious enough offense to have been reincarcerated." Other short-term results: 123 out of 145 students completed two quarters of work on campus, 9 received A.B. degrees, while 7 more had enough credits which were not properly distributed.

One unanswered problem with these kinds of studies is the absence of reported success for individuals. Concerned with statistics, we miss what these programs may mean to individual prisoners. Habenstreit (1973) has presented a series of case studies about study release from the perspective of the inmate student. No attempt is made to evaluate the program or to indicate recidivism rates, but it helps the reader understand the difficulty of readjusting to the community for some inmates. tured prison environment, they tend to feel disoriented and 
they usually flounder about while trying to adjust. In such a situation, the easiest thing to do is to revert back to the life style they knew before they were imprisoned. At least, it is familiar while everything else is so strange. This is one of the reasons recidivism rates are so high. (Habenstreit, 1973, p. 243) 
CHAPTER $V$

VOCATIONAL EDUCATION AND TRAINING

Studies of the effect of vocational training offer mixed and often contradictory conclusions. Some report a high success rate while others indicate higher recidivism among training groups than among nonparticipants. In some programs, training leads to employment, since employment is an integral step in the training process. Other programs offer no job assistance when the inmate is released. Many programs have such short-term involvement for some clients that it becomes difficult, if not impossible, to gather evidence of the post-release effects of training. This was the case in the Oregon State University Study.

Vocational training did not have any effects and the difficulty is that so few respondents who were sampled had completed training that no effect could be found. The total sample of V.T. participants was low. Furthermore, our analysis showed that much larger samples of V.T. graduates had to be selected in order to detect significant effects. There was evidence that frequent non-completion of V.T. was produced by early release for parole and work. . . (Mason et al., 1978, p. 3)

Out of the original sample of two hundred inmates released from Oregon State Penitentiary and Oregon Correctional Institute, only twenty-four had participated in V.T. Only fifteen of these had enough involvement to measure and, of these, only four had completed the training. "These numbers are too low for testing of treatment effects with adequate precision" $(p, 10)$. The authors suggest that judging from V.T. records, the effects of training could be measured if all who completed the vocational program in any given training period were compared with 
a matching group of those who participated but did not complete training, and with a third group whose members did not participate in V.T., assuming that all groups would have been released in the same year for follow-up purposes (pp. 46-47).

Mace (1978) reported a very high success rate for those who participated in vocational training with only a 3 percent rate of recidivism over four years of follow-up. However, most of those who received vocational training were not employed in their skill area. This reported success rate is incredibly high and one suspects that available employment had a strong effect in this study. In fact, the employment factor was strongly related to both monthly income and parole success, as indicated by the fact the mean income of trainees was not significantly different than the mean income of those who were not trained. Nevertheless, the study found the difference in parole success between those who participated in training and those who did not participate was significant at the .02 level of confidence after one year of follow-up, and to the .003 level of confidence after three years of follow-up. The author suggests the fact that many, with or without training, found employment as truck drivers, earning good wages, may have been an unusual factor in this particular study. At the same time, this fact emphasizes the importance of employment to success on parole (pp. 125-26).

Hal Boyle's (1978) study of vocational training effects is reported at length in this chapter because it seems to be the most thorough study available on the subject. His research attempts to:

- . evaluate the impact of vocational education on ex-inmates at Lexington Regional Training Center. This evaluation is a follow-up of released prisoners from two situations: Those who have not participated in any vocational training and those 
who have successfully completed training in a trade at Lexington. Does vocational training aid the incarcerated individual in return to society? (Boyle, 1978, p. 4)

Boyle's study begins with a brief review of research in correctional literature, which tends to support the remarks that were made at the beginning of this chapter. He observes:

Some studies find that those trained tend to have a lower percentage of recidivism, others find higher rates. In terms of job stability and unemployment, research indicates contradictory findings. In some cases, those trained have higher job turnover after release than those not trained. In other research, those trained appear more stable. No clear indication is given that vocational training programs aid in changing the personality of inmates. (Boyle, 1978, p. 19)

These confusing and often contradictory results can sometimes be traced to inadequate research methods. The author suggests more research would help determine what type of persons benefit most from vocational training, as well as defining the kinds of auxilliary services which might enhance the training experience and lead to higher success rates.

The study also illustrites the difficulty one may expect to encounter in attempting such research. Mr. Boyle selected 156 potential subjects from the study population, which consisted of all inmates who were released from the Lexington Center in 1976. From this original group, released on probation or parole, he assumed as many as fifty would choose not to be interviewed for one reason or another. He hoped to find about fifty clients who had completed vocational training before they were released in 1976, and another fifty persons who had not participated in training but were also released the same year. Finally, for reasons which cannot be described at length here, he eventually succeeded in locating and interviewing fifty of the group originally 
selected. Of these, thirty-four had participated in vocational training and sixteen had not. The author admits that the size of the sample is an inherent weakness in this particular study.

The subjects are essentially an availability sample of all persons released on parole from the prison. Therefore, without qualification, the data collected may not be representative of the parameters of vocational training impact. (Boyle, 1978, p. 24)

Data for the study were derived from the following sources:

(1) interviews with the releasees while they were on parole; (2) scores on The Sixteen Factor Personality Inventory, administered early in each inmate's period of incarceration; (3) interviews with the vocational training counselor; and (4) scores on the same personality test given after release or at the time of the final interview.

The attempt to measure the effect of training through testing requires further explanation. The experimental group members were given the test on three occasions: at the time of classification, again after completing vocational training, and finally, when they were interviewed. The control group was tested on the first and last occasions only. Analysis of variance tests and tests of significance were applied to determine if change occurred after vocational training. "Theoretically, we should find significant changes in the test scores of trained but not in the scores of those who have not participated in the vocational training program." Also, comparing the scores of the experimental and control groups on the first test:

. . we would theoretically expect to find . . no significant difference.. . but since the trained sample has the benefits of the program, a significant difference of mean scores at the time of the interview. By using these procedures we can determine if the training program is positively changing personality factors of inmates. (Boyle, 1978, p. 26) 
Each factor of the test was analyzed separately and the results are explained at length. We can only present a general review of the findings here, even though such a summary may not do justice to the author's work.

There is really no evidence that training changes personality. It does, however, seem to accent certain characteristics or differences between the two groups of subjects. Dominant persons are more likely to be selected for training programs than submissive individuals. Perhaps because they are more aggressive socially, they seem better able to take advantage of opportunities which may "ease their stay in prison" or "improve their chances of early release." However, although this difference between the groups was quite apparent at the time of the first test, it was not apparent in the last test (p. 67).

Vocational training may retard the effects of institutionaliza'tion or diminish the development of more passive characteristics such as a disproportionate sense of guilt or self-reproach. Conversely, those who are trained appear to be less apprehensive about their role in the community, while members of the untrained group seemed to experience high levels of anxiety shortly after their release. Here again, it might be inferred training helps in the readjustment process, were it not for the fact that trainees had higher recidivism rates than the untrained.

Other measures of the effectiveness of training included job stability, earnings, and recidivism. The study found no significant differences between the groups on any of these. "Vocational training does not appear to enhance job stability as compared to those not trained" 
(p. 93). Also, differences in earnings between the two were not significant. Furthermore, it "was determined that no significant difference exists between the two groups on recidivism." In fact, the trend was opposite to expectations. "Using Yule's Q, it was found that those trained had a slightly greater likelihood of being recidivist than those not trained" (p. 94). The rate of recidivism among experimental group members was 38 percent compared with a 25 percent rate among the control group members (p. 39).

Also, as is evident in other studies, most inmates who participate in vocational training do not work at their learned skill after they are released. Among those who were employed at the time of their interview, only 20 percent were working in their skill area (pp. 51-52).

There were other interesting and sometimes confusing results of this study. Younger rather than older offenders were more likely to benefit from vocational training. Black persons who were trained were not as likely to be recidivists as white persons who were trained, compared to their respective groups who were not trained. And strangely enough, among those who received training, persons with prior incarcerations had lower recidivism rates than first offenders. Nor was there any apparent correlation between recidivism and time spent in prison, among those who were trained (pp. 42-47).

Most of the trainees were released to a halfway house or community treatment center for a period of work release prior to their parole date. It is widely assumed that this kind of supervised transition experience aids in release adjustment. However, no such effect was apparent in this study. Those trainees who were released to a C.T.C. had 
higher recidivism rates than trainees who were not assigned to such a center (p. 49).

Because of the scope of his research, some of Mr. Boyle's recommendations are worth considering. He suggests better classification procedures and more research would help in selecting candidates who are most likely to benefit from vocational training. Also:

. . vocational training should not be coercive, either overtly or covertly. . . . This would eliminate persons from the program who are merely putting a pseudo face for the parole board. This would allow more of those who really want to learn a trade to enroll as well as allowing more space for training. (Boyle, 1978, p. 110)

Finally, it would be best if vocational training programs could develop their own reentry systems rather than depending on work release opportunities offered through a correctional training center (p. 110).

Very similar recommendations were offered at the conclusion of the Windham School study which was discussed briefly in the last chapter (Monroe et al., 1975): (1) more attention should be given to vocational training at classification; (2) more effort in job placement is needed, particularly in skill areas where training has been completed; and (3) training needs constant reevaluation in regard to the job market.

VOCATIONAL TRAINING FOR WOMEN INMATES

There is relatively little information pertaining to vocational training in institutions for women. One survey (Spitz, 1976) indicates that training programs for women developed late, most of them beginning after 1972. Currently, a wide variety of vocational skills are offered at various institutions and it is anticipated that lower recidivism 
rates will be reflected as results become available.

. . by improving legitimate opportunities, we are making illegitimate opportunities less desirable. A person with a good job has less to gain and more to lose if he/she is caught performing a criminal act. By improving a person's employability, we are increasing the cost to him/her of engaging in criminal activity. (Spitz, 1976, p. 36)

The theory seems sound enough but results from available statistics were said to be disappointing. However, those statistics were quite limited. According to the survey, "only $35 \%$ of existing programs maintain followup statistics on women leaving their institutions" (Spitz, 1976, p. 36). 
CHAPTER VI

\section{CONCLUSIONS}

What conclusions might be reached as the result of evidence offered in the present review? In evaluating various research efforts and attempting to summarize the results, it is apparent that we do not have conclusive evidence of the effects of education on recidivism. While more of the studies offer evidence in support of education than against $i t$, the difference in recidivism rates is not statistically significant in most cases. Therefore, we must conclude that the results may be due to chance or to other effects than education.

There were some studies in which results were statistically significant. Mace (1978, pp. 125-26), for example, found significantly lower recidivism rates for those who participated in vocational training, but on the other hand, Boyle (1978, p. 39) found higher recidivism rates among those who had been enrolled in vocational training than among those who did not receive training. Therefore, it is clear that we cannot say from the evidence that has been presented that prison education and training programs reduce recidivism. It is also fair to say that it cannot be assumed, either, that such programs fail in reducing recidivism.

It should be noted that many professionals in corrections object to the use of recidivism as the primary measure of program success. Sherman Day, former Director of the National Institute of Corrections, 
and also former Assistant Director of the U.S. Bureau of Prisons, has said:

I would not tie the success of vocational education programs to recidivism. . . Can you deal with a lifetime of failure, regardless of circumstances, and correct that failure by completing a welding course? Can you hold a welding course responsible for insuring that a thirty-three year old, who has had multiple failures in our society, will not fail again? It's an unfair test. Basically, the point I'm trying to make is that correctional institutions can't be held responsible for the recidivism rate of the offenders. (Day, 1979)

My own conclusion, after completing the study, is that other measures of the effect of education and training programs could well be used, along with recidivism, in the attempt to determine whether or not such programs succeed in rehabilitating criminal offenders. Another important area of research review for anyone who is interested in further investigation might be concerned with other outcome measures, such as: inmate evaluation of programs, achievement records or skill improvement, the results of personality or attitude tests, etc., as criteria by which to evaluate the effects of education programs. It would be interesting to note how measures such as these would compare with recidivism in reviewing program success. Since the goal of this particular study was to evaluate the effects of prison education programs on recidivism, we have not been concerned with other criteria, except where other measures have been presented along with recidivism as evidence of the effects of certain programs. Nevertheless, research which offers a wider basis for judgment is clearly needed.

Another question that needs to be addressed concerns the quality of teaching in prison education programs and what effect this may have on various measures of program success. The latest available survey 
indicates that the quality of prison education has improved steadily and that instruction at the high school level usually involves certified teachers. However, it is not clear that similar standards exist for instruction at the college level, or to what extent teachers are evaluated, either by administrators and/or students. Obviously, teacher effectiveness and the effect of the teacher's personality on the students may be related to program outcomes. The importance of the teacher as a role model could hardly be overemphasized. The teacher's own values, as well as his/her professional skill and dedication, may lead to recognition of more acceptable social values and/or careers on the part of students; or, if the teaching effect is negative, it may lead to reinforcement of criminal values and interests. The challenge of teaching in prison education programs becomes very significant when seen in these terms.

Also, it should be noted that there is evidence from several studies that long-term involvement in education or training is more effective in rehabilitating offenders than short-term participation. Therefore, why not employ a different approach than the traditional use of such programs as preparation for release? Why not consider applicants with longer sentences who may wish to learn a skill or trade as a legitimate means of making better use of their time in prison? Any gains in status or achievement that might result from such training would likely be to the good, quite apart from the question of eligibility for release.

Another suggestion might be to consider returning those who have failed on release to further education or training in their skill area, 
rather than washing them out of programs because of failure. Continued follow-up when they are released again would be desirable, comparing these subjects with other recidivists who did not reenter training in their skill area or participate further in education. Such an approach would surely provide more conclusive evidence of the value of rehabilitation programs than the attempts to evaluate short-term involvement in most current studies.

On the other hand, if deemphasizing recidivism were to have the effect of reducing concern with research, that would be most unfortunate. Boyle's point of concern is well taken here:

Treatment programs cannot ride the rhetoric of theory without evaluation. The impact of treatment must be continualiy assessed. Social Scientists must ask the question, how effective is the program? Treatment without a grounded foundation reeks of social irresponsibility. Although plagued with methodological problems, research evaluation of rehabilitation strategies should continue to assess the impact that strategy has on those it is intended to serve. (Boyle, 1978, p. 113)

Beyond this, it should be recognized that education and training programs are not about to be abandoned in corrections. Those who are likely to be making decisions concerning these programs, the administrators of correctional institutions across the country, are not convinced such programs have been a failure, although they admit that changes are needed and that programs should be improved. They also recognize research and evaluation must be emphasized more in the future than they have been in the past.

A survey of correctional administrators found that 63 percent feel that some rehabilitation programs work and 75 percent feel that there is not enough evidence to throw out the concept. 
Emerging from this dispute is a truth totally shattering:

there is still . . . very little hard evidence on which to base decisions in an area of crucial concern to the nation. Useful measurements of any kind in corrections are exceedingly difficult to produce, but more must be attempted. (Serri11, 1975)

There seemed to be general agreement, in response to the Serrill (1975) survey, that some programs work for some people and not for others, and more careful selection procedures should be used in placing people in programs rather than adopting programs for all inmates in an institution. My own conviction is that more selective research attempts are needed to determine which individuals or groups of inmates are most likely to benefit from programs. Equally important is to determine what types or combinations of programs may prove to be successful with certain individuals and groups.

Programs should be designed with continued training and follow-up in mind. Vocational training should lead to on-the-job training and to apprenticeship training whenever possible. For those who successfully complete G.E.D. training, enrollment in college work should be encouraged with the understanding that satisfactory progress at this level may lead to study release consideration for those who can satisfy both academic and security status requirements. Special support services and supervision might be considered for those who have made significant progress in education and training programs, after they are released.

In order to facilitate research on program effects or outcomes, it is important to keep adequate records which may assist the research process. Any information which might later prove to be useful data should be recorded. Admittedly, it may be difficult to administer education and training programs that are designed to measure results. 
However, if groups can be defined after clients have enrolled as a matter of individual choice, then the parameters of the program could be defined as early as possible, and the subjects followed long enough for valid measurements to be obtained.

Daniel Glaser, whom many regard as the dean of the science of correctional rehabilitation, has advocated programs designed according to "relevant behavioral and social science theory," in which procedures for evaluating the program are then established to test the theory.

Traditional evaluation starts with whatever cases have been handled at a particular agency or program . . . In contrast, theory grounded evaluation begins with abstract potentially policy guiding ideas from which one can deduce the consequences that should be expected with a particular type of subject. The research is then designed to see whether these consequences do occur. (Glaser, 1977)

As an example, he cites certain principles of learning theory; for example, that people tend to repeat behavior in which the circumstances have been rewarding. Only if punishment lasts and is unavoidable does it stop or deter repetitive behavior, or, unless alternative conduct is as rewarding as the original behavior.

From these principles it follows that punishment for delinquency or crime, whether an official penalty or the informal social consequences of arrest, reduces recidivism only if it results in the subject's perceiving alternatives to crime as more gratifying than criminal behavior. (Glaser, 1977)

It is clear that establishing experimental programs along the lines suggested and evaluating them properly will require a good deal of planning and expertise. Correctional institutions might consider employing a research person, or state correctional departments might provide the services of a consulting firm in designing programs which have a clearly defined goal and the means to measure the results. I 
suggest that programs offered in the past have been too broad, have been designed to include too many, and have tried to cover too much. Education and training efforts should be scaled down so that learning opportunities are provided in which clients are anxious to participate.

\section{RECOMMENDATIONS}

Basic and G.E.D. Education

There is evidence of great improvement in prison education at this level in recent years. Short-range measures of the effect of these programs are as important as long-range outcomes. Whether or not basic education should be mandated for inmates who fall below a certain level is a question best left to correctional administrators and educators. It is a sound principle that voluntary participation is to be preferred to required programs.

My own view is that those who participate in education programs at any level should be enrolled on a part-time basis. If schedules were arranged so that students could spend a half day at school and a half day at a work station or assignment, this would help overcome the stigma, often associated with prison education programs, which suggests those who enroll in school are avoiding work or seeking easy time. If some evening classes could be scheduled, these would provide the opportunity for education for those who work full-time as well as for students who prefer to work at a faster pace.

There is also evidence to support the conclusion that involvement in education or training should not affect parole consideration. This kind of information is no longer furnished to parole boards in the 
federal system. Such an approach will help overcome a problem that is commonly recognized: of enroliting in programs to impress the parole board or manipulate the system. If changes in behavior are to be recognized, they could probably be communicated through various institutional reports, or some means of referral for testing could be devised. Most experts in corrections now favor flat sentencing with programs available for those who want to take part, and with release consideration no longer contingent on participation in rehabilitation programs.

Emphasis should be placed on some measure of achievement or the completion of some part of a program. Those whose sentence framework is such that they are unlikely to complete work in the program should be discouraged from enrolling.

\section{Post-secondary Education}

The emphasis should be on quality education with limited enrollment. Some of the courses that are requisite to most undergraduate programs, along with other courses in which there is a known interest among potential students, could be arranged in a schedule which might extend over two or three years. There should be enough flexibility to provide work for the long-term inmate who develops a continuing interest in education as well as for the short-termer who chooses to get started in college work while he/she is in prison. Again, the time frame for any student should be such that he/she will be able to complete the term for which enrolled.

I believe we will see a renewed interest in study release in correctional education in the near future. Students should be carefully selected for these programs with input from the prison school, and 
custody and psychology departments as well as caseworkers. Only those who have participated in the prison school program and demonstrated interest in and ability for college work should be considered for campus study release. In my opinion, the Minnesota Newgate Program (Cleneden et al., 1979) serves as a model, with participation remaining quite limited and eligibility contingent upon a parole date.

\section{Vocational Training}

These programs have a great deal of need for improvement, since they have not enjoyed much success, either in the use of training skills or in the reduction of recidivism rates. They appear to be subject to manipulation more than other programs. Evidence tends to show they attract those who enroll for other reasons than learning a skill, such as those who desire a change, who want to do "easy time," or who are looking for early release.

Evidence of such problems was described in the study by Mason, Seidler, and Lowry (1978), as cited in Chapter V. They found so few persons who enrolled in vocational training completed the program that it was not possible to measure the effect of the program. Their work suggests more attention should be given to coordinating vocational training with release considerations in order to avoid one program interfering with the other (pp. 3, 10, 46-47).

To overcome these problems, I submit that completion of the training program should precede parole consideration. Those who apply for training should be given the clear understanding that if they become eligible for parole consideration during the training period, their parole date will be set beyond the completion of training, and those who 
drop out of training will be scheduled for parole consideration after the end of the training period in which they were enrolled. Such standards might well reduce the number of those who participate in vocational training and this, in turn, would allow vocational instructors more time and space for working with each client.

Also, it is certainly desirable to develop vocational training schedules which allow for a limited period of on-the-job training in the community at wages that are commensurate with training or apprenticeship status. Not only would this help in job development, but also it would improve the chances of successful parole. 


\section{A SELECTED BIBLIOGRAPHY}

Bailey, C. A. 1975. Rehabilitation has been a failure. Corrections Digest $(6: 9)$, pp. 8-9.

Bean, P. 1976. Rehabilitation and deviance. London \& Boston, Rutledge and Keagan Paut.

Beha, J. A. 1977. Innovation at the County House of Corrections and its effects upon patterns of recidivism. Journal of Research in Crime and Delinquency (14:1), pp. 88-106.

Bell, R., Conrad, E., Laffey, T., Lutz, J., Miller, P., Simon, C., \& Stakleton, A. 1979. Correctional education programs for inmates --the issues: National evaluation: Phase I report. Bethlehem, Pennysivania, Lehigh University.

Blake, McKelvey. 1977. American prisons, a history of good intentions. Montclair, New Jersey, Patterson Smith Publishing Co.

Boyle, H. 1978. A follow-up evaluation of the effectiveness of a medium security state prison's vocational training program on parolees. Doctoral Dissertation, Oklahoma State University.

Carter, R., Glaser, D., \& Wilkins, L. 1977. Effectiveness of correctional education at correctional institutions (a pamphlet). Philadelphia, Pennsylvania, J. B. Lipincott.

Clement, D. \& Horn, J. 1978. A behavioral approach to reducing recidivism. Psychology Today $(11: 11)$, pp. 35-36.

Cleneden, R, Ellingston, J. \& Severson, R. 1979. Project Newgate--the first five years. Crime and Delinquency (25:1), pp. 55-64.

Csapo, M. \& Agg, B. 1976. Educational rehabilitation of delinquents in a community setting. Canadian Journal of Criminology and Corrections $(18: 1)$, pp. $42-4 \overline{8}$.

Cuddey, E. 1977. College for convicts. Progressive (41), pp. 53-55.

Day, S. 1979. Education and training in the criminal justice system: Implications for vocational education R. \& D. The National Center for Research in Vocational Education, Columbus, Ohio.

Erickson, R., Crow, W., Zurcher, L. \& Connett, A. 1975. Paroled but not free. New York, N.Y., Behavior Publications. 
Feldman, S. E. 1975. Trends in offender vocational and education programs--a literature search with program development guidelines. A paper presented to the American Association of Community and Junior Colleges.

Galley, J. \& Parsons, M. 1976. College behind the walls--factors influencing a post-secondary inmate education program. A paper presented at the Community College Social Science Association National Convention at Kansas City, Missouri.

Glaser, D. 1964. The effectiveness of prison and parole systems. New York, N.Y., Bobbs MerrilT Co.

Glaser, D. 1975. Achieving better questions: A half century of progress in correctional research. Federal Probation $(39: 3)$, pp. 3-9.

Glaser, D. 1977. Concern with theory in correctional evaluation research. Crime \& Delinquency $(23: 2)$, pp. 173-79.

Gubser, M. 1977. Prospective teachers sent to prison. Journal of Teacher Education (28), pp. 22-25.

Habenstreit, E. 1973. To my brother who did a crime. New York, N.Y., Doubleday.

Holden, C. 1975. Rehabilitation is suffering a collapse. Science (188), pp. 815-17.

Holden, C. 1978. Controversial prison clings to beliefs in rehabilitation. Science (199), pp. 665-68.

Johnson, D., Sharon, R. \& Britton, G. 1974. Correctional education and recidivism in a women's C.C. Adult Education (24:2), pp. $121-29$.

Kassenbaum, G., Ward, D. \& Wilner, D. 1971. Prison treatment and parole survival: An empirical assessment. New York, London Sydney \& Toronto, John Wiley \& Sons Inc.

Kitchener, H., Schmidt, A. \& Glaser, D. 1977. How persistent is postprison success? Federal Probation (41:1), pp. 9-15.

Lamott, K. 1974. Topics and comment: Bankrupt prison reform. Center Magazine $(7: 5)$, p. 75 .

Lavin, J. H. 1977. Changing 1ives. Change (9:12), pp. 49-50.

Lewis, M. V. 1973. The humanities in prison. Prison Journal (53:2), pp. 26-35. 
Lipton, D., Martinson, R. \& Wilks, J. 1975. The effectiveness of correctional treatment: A survey of treatment evaluation studies. New York, N.Y., Praeger Publishers.

Mace, J.L. 1978. The effect of correctional institutions' education programs on inmate societal adjustment as measured by post-release recidivism. Doctoral Dissertation, West Virginia University.

Malloy, M. T. 1975. Reform is a flop. The National Observer (14:1), p. 1 .

Marsh, J. 1973. Higher education in American prisons. Crime and Delinquency Literature $(5: 1)$, pp. 139-55.

Marsh, J. 1973. Philosophical considerations of prison education: Pro and con. In Reagan, Stoughton, Davis \& Smith. School behind bars, pp. 1-44. Syracuse, N.Y., Syracuse University Research Corporation,

Marsh, J. \& Adams, S. 1973. Prison education tomorrow. In Reagan, Stoughton, Davis \& Smith. School behind bars, pp. 133-52. Syracuse, N.Y., Syracuse University Research Corporation.

Martin, K. 1973. A brief history of prison education. In Reagan, Stoughton, Davis \& Smith. School behind bars, pp. 45-68. Syracuse, N.Y., Syracuse University Research Corporation.

Martinson, R. 1974. What works? Questions and answers about prison reform. The Public Interest (35), pp. 22-54.

Martinson, R. 1975. Nothing works: Excerpts from an address by Dr. Martinson at the American Correctional Association workshop. Corrections Digest $(6: 18)$, pp. 4-6.

Mason, R., Seidler, A. \& Lowry, H. 1978. A study of post-release outcomes for participants in prison training programs. Corval1is, Oregon, Survey Research Center, O.S.U.

McCollum, S. 1975. Post secondary education programs for prisoners. Washington, D.C., Bureau of Prisons, U.S. Department of Justice.

McWilliams, J. P. 1971. Rehabilitation versus recidivism. Junior College Journal (41), pp. $88 \mathrm{ff}$.

Monroe, W., Robinson, R. \& Smith, C. 1975. Cooperative follow-up report of the Windham School District and the Texas Department of Corrections. Huntsville, Texas, Texas Department of Corrections.

Nagel, W. 1973. The new red barn: A critical look at the modern American prison by the former Director of the Bureau of Prisons. Washington, D.C., Library of Congress. 
Reagan, M., Stoughton, D., Smith, T. \& Davis, J. 1973. School behind bars: A descriptive overview of correctional education in the American prison system. Syracuse, N.Y., Syracuse University Research Corporation.

Salmony, L. 1974. Corrections in Oregon: A way to proceed. A report to the Oregon State Corrections Education Committee. Salem, Oregon, The Oregon State Corrections Commission.

Serrill, M. S. 1975. Is rehabilitation dead? Corrections Magazine $(1: 5)$, pp. 3-10.

Spitz, J. 1976. Overview of manpower programs for incarcerated women. A thesis submitted to Northeastern University College of Criminal Justice.

Stoughton, D. \& Reagan, M. 1973. Prisoner education today. In Reagan, Stoughton, Smith \& Davis. School behind bars, pp. 69-132. Syracuse, N.Y., Syracuse University Research Corporation.

Stout, R. J. 1975. One of the luckier ones. Commonweal (104), pp. 463-65.

Stroman, D. L. 1973. An evaluation of corrections education coordination program. Huntington, Pennsylvania, Pennsylvania Department of Justice.

Taggart, R. 1972. The prison of unemployment: Manpower programs for offenders. BaTtimore, Maryland, Johns Hopkins University Press.

Taintor, J. B. 1977. Vocational rehabilitation of youthful offenders in the State of Florida. Doctoral Dissertation, Florida State University.

The Correctional Education Association International Conference. 1976. Changing times for the adult correctional educator. A paper presented at the Correctional Education Association International Conference. Tampa. Florida, The University of South Florida.

Wooldridge, S. 1976. College for prisoners: Ohio's open door. Change (8:9), pp. 17-24. 